\title{
Aging and the neuroeconomics of decision making: A review
}

\author{
STEPHEN B. R. E. BROWN AND K. RICHARD RIDDERINKHOF \\ University of Amsterdam, Amsterdam, The Netherlands
}

\begin{abstract}
Neuroeconomics refers to a combination of paradigms derived from neuroscience, psychology, and economics for the study of decision making and is an area that has received considerable scientific attention in the recent literature. Using realistic laboratory tasks, researchers seek to study the neurocognitive processes underlying economic decision making and outcome-based decision learning, as well as individual differences in these processes and the social and affective factors that modulate them. To this point, one question has remained largely unanswered: What happens to decision-making processes and their neural substrates during aging? After all, aging is associated with neurocognitive change, which may affect outcome-based decision making. In our study, we use the subjective expected utility model - a well-established decision-making model in economics - as a descriptive framework. After a short survey of the brain areas and neurotransmitter systems associated with outcome-based decision making - and of the effects of aging thereon — we review a number of decision-making studies. Their general data pattern indicates that the decision-making process is changed by age: The elderly perform less efficiently than younger participants, as demonstrated, for instance, by the smaller total rewards that the elderly acquire in lab tasks. These findings are accounted for in terms of age-related deficiencies in the probability and value parameters of the subjective expected utility model. Finally, we discuss some implications and suggestions for future research.
\end{abstract}

Decision making is usually defined as the process of considering several alternatives and choosing the optimal one (Frank \& O'Reilly, 2006; Sanfey, 2007b). The consequences of the choices we make vary in impact (e.g., which newspaper vs. which house should I buy?). However, most decision-making tasks used in the lab are strongly simplified (e.g., do I choose a $\$ 1$ reward now or a $\$ 5$ reward later?).

The newly emerged field of neuroeconomics - a combination of neuroscience, psychology, and economicsfocuses on the neurocognitive processes underlying economic decision making and outcome-based decision learning, as well as individual differences in these processes and the social and affective factors that modulate them, by using realistic tasks. One well-known example is the Ultimatum Game, in which 2 participants need to divide money. The first player proposes a division scheme; if the second player accepts the suggestion, the money is divided as planned. However, if the second player refuses, no one gets any money. This realistic task is suitable for use in an fMRI scanner (with either a real or a computersimulated proposer) and has led to insight into the neural substrata underlying a specific form of economic decision making (for a review, see Krueger et al., 2007). In addition, this game, unlike many standard lab tasks, takes social interaction into account.

Building on combined insights from behavioral economics, experimental psychology, and the cognitive neu- roscience of reward processing, recent neuroeconomics research (Sanfey, 2007b; van Winden, Stallen, \& Ridderinkhof, 2008) has revealed a number of key themes: First, what are the differences and similarities in the neural processing of monetary vis-à-vis social rewards; second, what is the role of emotions and affective processes in economic decision making and outcome-based decision learning; third, how are our decisions modulated by our understanding of the intentions of others? The brain circuits (most prominently the striatal reward circuitry, the orbitofrontal cortex [OFC], the medial frontal cortex [MFC], and the insula) and neurotransmitter systems (most prominently the dopamine system) associated with each of these themes will be discussed in detail in the next section.

One question that arises in neuroeconomics is whether and how decision-making and learning processes are affected by aging. Aging is often accompanied by structural and functional neurocognitive change (see, e.g., Bäckman, Nyberg, Lindenberger, Li, \& Farde, 2006) that may well influence decision making, and the elderly have to make many consequential decisions in daily life, both before and after retirement. The number of elderly people and their longevity have increased in both the United States and Europe (Kovalchik, Camerer, Grether, Plott, \& Allman, 2005; Mather, 2006); for instance, in the Netherlands, the percentage of people over 65 years of age has 
increased from $6 \%$ in 1900 to $14 \%$ in 2007 (and is estimated to be $24 \%$ by 2050 ). The elderly therefore make up an increasingly significant part of the population, and their decisions can influence our society's economy and politics (Kovalchik et al., 2005); thus, it is important to study their economic decision-making processes. Poor decision makers, and especially older decision makers, have been shown to be particularly vulnerable to deceptive advertising (Denburg et al., 2007).

A major question that arises is whether the decisionmaking and -learning processes of the elderly actually differ from those of younger persons. For instance, a common assumption holds that the elderly may be more conservative in decision making, but scientific evidence for this assumption is scarce and inconsistent (e.g., Chou, Lee, \& Ho, 2007; Deakin, Aitken, Robbins, \& Sahakian, 2004; Mather, 2006). Related to this assumption is the purported positivity bias of elderly participants: Elderly people are often thought to display a tendency to ignore or even avoid negative information (or decisions associated with negative outcomes) in favor of positive information. Although evidence in favor of such a bias has been reported (see, e.g., Mather \& Knight, 2005), the existence of the positivity bias has not been unequivocally established. For instance, when elderly participants were distracted during task performance, they paid more attention to negative than to positive stimuli (Knight et al., 2007). Although a thorough evaluation of the positivity bias in older adults is beyond the scope of this article, evidence in favor of such a bias will be presented occasionally. In any case, this bias should be kept in mind while interpreting neuroeconomic decision-making results (see the section on conceptual issues of aging and decision-making research, near the end of this article).

\section{A Model of Decision Making}

The processes associated with decision making have been captured in a number of models. One of these is the subjective expected utility model (e.g., Sanfey, 2007a; Sanfey, Loewenstein, McClure, \& Cohen, 2006), which defines the utility attached to each given outcome as the product of the probability and the value of that outcomethat is, utility $=\Sigma p\left(x_{i}\right) u\left(x_{i}\right)$, where $p$ is the probability and $u$ the subjective value of a possible outcome. As an illustration, consider Figure 1, in which the following example is depicted.

As you go to work, you look outside and decide that it might rain today. Therefore, you are presented with a choice - to bring an umbrella to work, or to leave it at home (taking the risk of getting wet). As can be seen in the figure, each choice is associated with two possible outcomes: It might or might not rain. To demonstrate the ro-

\section{Options Outcomes Probability Value Expected Utility}

(\%)

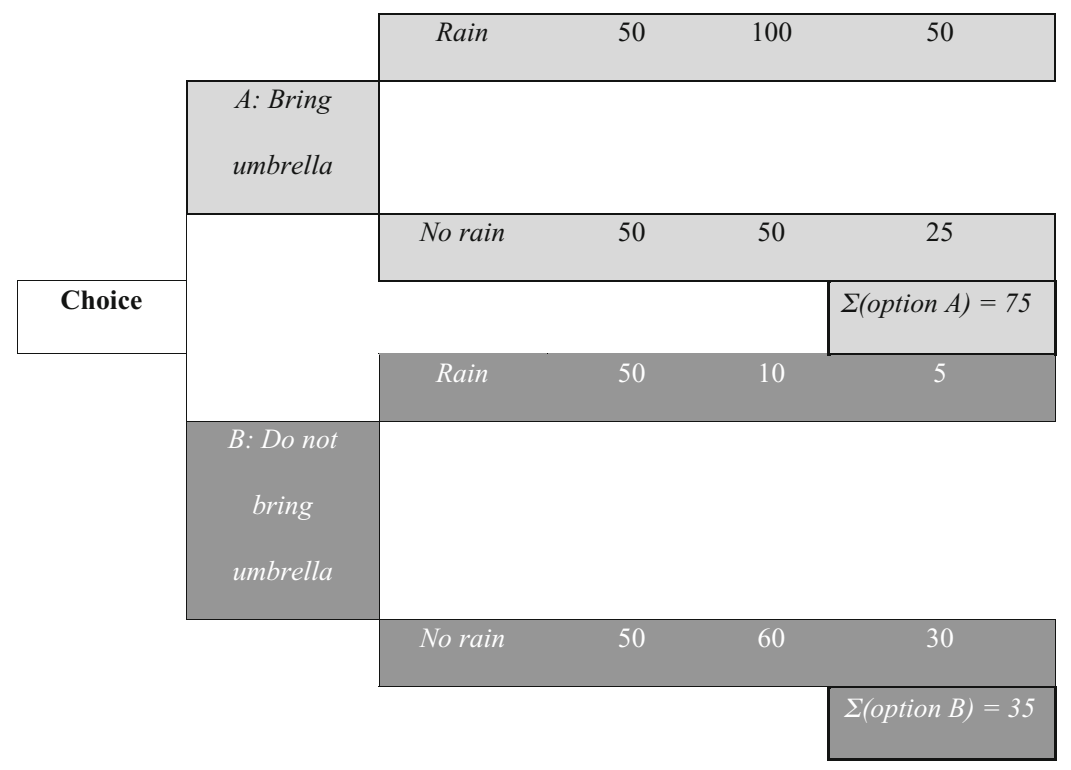

Figure 1. An illustration of the subjective expected utility model, depicting the "steps" involved in the model. In the illustration, a decision maker starts with a dichotomous choice (to bring or not bring an umbrella to work). Each option is associated with possible outcomes (rain or no rain), and each outcome has a given probability. To illustrate that this model works, to some extent, even under conditions of uncertainty, these probabilities have all been set to $50 \%$. Finally, an expected utility is calculated by multiplying the probability and value for each outcome. These utility values are then summed per option; the higher this total value, the more desirable is the associated option. In this illustration, bringing an umbrella to work is more desirable than not doing so, regardless of whether it rains. 
bustness of the model, these options are given equal probabilities of occurring (a 50\% chance). The four options (umbrella and rain, umbrella but no rain, no umbrella and rain, no umbrella and no rain) are each awarded a subjective value (the higher the value, the more desirable the outcome). These values can be pretty much anything: They are subjective, and they can be used by the decision maker to arrange the given options on a scale from most to least desirable. As can be seen in the figure, the highest value is given to bringing an umbrella and there being rain (after all, in this situation, one might be happy to have brought an umbrella). On the other hand, the option of not bringing an umbrella and so being rained on is awarded the lowest subjective value (because one will get wet). Finally, the subjective expected utility is calculated by multiplying the probability and value parameters; again, the higher this value, the more desirable it is. The various subjective utilities associated with each outcome are then summed, with the highest value representing the most desirable choice. As is apparent from the figure, bringing an umbrella to work is the most optimal choice, whether it rains or not.

Although this model is a simplification of neuropsychological decision-making processes, it is parsimonious, and its parameters and outcome variable have been related meaningfully to activation in various brain circuitries. Therefore, the subjective expected utility model may serve as a valuable and-perhaps more importantlyrepresentative example of a guiding framework for describing the processes associated with decision making. As stated above, the model consists of two parameters and an outcome variable, utility. The utility of a given possible outcome is calculated by multiplying the probability and the subjective value of that outcome. Because of its parsimonious and relatively straightforward nature, this model can be applied to many economic decisionmaking tasks, rendering it useful - though obviously not exclusive - as a descriptive framework for understanding outcome-based decision making in a variety of laboratory paradigms. Moreover, in view of the link of the model to brain areas, it may also aid in making predictions regarding the effects of aging, because the age-related effects on many of the brain areas associated with this model have been well charted in the literature.

\section{Goals of This Article}

The goals here are twofold. First, we seek to ascertain whether there is any evidence for age-related alterations in economic decision-making processes and outcome-based decision making (caused by structural and functional brain decline related to aging). Second, we discuss pitfalls with regard to outcome-based decision-making research with older adults as participants, suggest some possible solutions, and outline directions for future research. To this end, a number of studies that address the issue of aging and outcome-based decision making will be reviewed. There does not appear to be a clear-cut definition within neuroeconomics of what constitutes a decision-making task. Therefore, in this article, a number of tasks that deal with decision making and decision learning under condi- tions of uncertainty, typically with the goal of maximizing reward, will be regarded as economic decision-making tasks. Examples would be the Iowa gambling task (discussed in a later section), which is known to recruit the ventromedial OFC (Bechara, Damasio, Damasio, \& Anderson, 1994), and probabilistic learning tasks (in which a participant's correct responses are rewarded according to a stochastic schedule-e.g., the probabilistic object reversal task described below), which have been indicated to recruit, among other areas, the striatum (see, e.g., Haruno \& Kawato, 2006). Probabilistic learning involves (economic) decision making because it relies on knowledge of previous choice-outcome contingencies. In this article, first we cover the brain areas and neurotransmitters associated with economic decision making and the effects of aging on these brain circuits. Then we review the literature on the neuroeconomics of aging, after which some conceptual and methodological problems are described, as well as some directions for future research.

\section{Brain Areas and Neurotransmitter Systems Associated With Economic Decision Making}

Economic decision making depends on a number of brain circuits and neurotransmitter systems, and many of these have been linked to the parameters of the subjective expected utility model (Sanfey et al., 2006), as detailed below. In this section, these parameters will be used as a guideline to survey the brain areas associated with economic decision making. Subsequently, two relevant neurotransmitter systems and their importance in economic decision making will be explored.

\section{Brain Areas Associated With \\ the Probability Parameter}

Several studies have begun to delineate the relation of the probability parameter of the subjective expected utility model to neural activation patterns (e.g., Sanfey et al., 2006). For instance, Knutson, Taylor, Kaufman, Peterson, and Glover (2005) showed that activity in the MFC correlates with anticipated gain probability. The dorsal striatum, in particular the caudate nucleus, has been linked extensively to computations of reward prediction error (i.e., the discrepancy between an expected reward and the reward actually received), which are based on calculations of reward probability (cf. Schultz, 2000, 2002). Reward prediction error computations in the dorsal striatum play a key role in linking reward to behavior (Knutson \& Cooper, 2005) and form the basis of action-contingency learning, the learning of probabilistic action-reward links (Balleine, Delgado, \& Hikosaka, 2007), and action-oriented decision making, in particular in the selection of actions associated with the greatest possible reward (Hikosaka, Bromberg-Martin, Hong, \& Matsumoto, 2008).

Note that a few studies have linked the ventral rather than the dorsal striatum to the probability parameter of the subjective expected utility model. For instance, Matthews, Simmons, Lane, and Paulus (2004) showed that the nucleus accumbens is activated during deliberation prior to the selection of risky as opposed to "safe" responses. 
Nonetheless, the dominant picture is that the ventral striatum represents reward magnitude (i.e., value; see the next subsection), whereas the dorsal striatum is associated with reward probability.

In the Prisoner's Dilemma game, participants estimate the likelihood that their cooperation will be reciprocated. Reward prediction errors in this task refer to the discrepancy between predicted and actual reciprocity. Positive reward prediction errors (as elicited by reciprocated cooperation) have been found to correlate with increased activity in the striatal reward circuitry, whereas negative reward prediction errors (elicited by unreciprocated cooperation) have been associated with decreased activation in that area (Delgado, Frank, \& Phelps, 2005; King-Casas et al., 2005; Rilling, Sanfey, Aronson, Nystrom, \& Cohen, 2004). For instance, activity of the dorsal striatum has been linked to the amount of reciprocity a participant had shown in previous trials; activation of the dorsal striatum appears to lead to increased cooperation in subsequent trials, thereby guiding decisions about reciprocity (King-Casas et al., 2005). Thus, the dorsal striatum (especially the caudate nucleus) appears to register social prediction errors as a guide for decisions about reciprocity (Sanfey, 2007a).

The ability to understand the inner motivations of others (often referred to as possessing a theory of mind) might be indirectly related to the assessment of outcome probability. After all, skills in divining and predicting a partner's mental states and intentions are crucial in decision-making tasks that require social interaction (be it cooperative or competitive) with a partner in order to maximize a reward. The capacity of theory of mind (often referred to as mentalizing) has been studied extensively-in part because of its suggested importance in autism - and a network of brain areas has been associated with it, most notably the anterior paracingulate cortex (APCC) and the posterior superior temporal sulcus (pSTS) (Amodio \& Frith, 2006; Baron-Cohen et al., 1999; Brunet, Sarfati, Hardy-Baylé, \& Decety, 2000; Gallagher \& Frith, 2002; Gallagher et al., 2000; McCabe, Houser, Ryan, Smith, \& Trouard, 2001; Saxe, 2006). Studies have indicated activity in both these areas when participants were involved in reasoning about and acting upon the beliefs and intentions of opponents during decision-making tasks (e.g., by trying to guess an opponent's strategy; Bhatt \& Camerer, 2005).

In the trust game, a two-person sequential game, the first player to move decides either to terminate the game (which leads to a fixed equal payoff to both players) or to let the other player (the trustee) choose between an option in which both players would be better off and an option in which the trustee would benefit but the first player would lose, as compared with the payoffs if the game were ended by the first mover. The APCC is activated when trustees make cooperative decisions - that is, when they choose not to be selfish but to go for the option in which both players benefit (Krueger et al., 2007; McCabe et al., 2001). Studies that have examined theory of mind by asking participants to mentalize about characters (instead of real human beings), on the other hand, have consistently observed activation of the pSTS area (Brunet et al., 2000; Castelli, Happé, Frith, \& Frith, 2000; Gallagher et al., 2000). It has been suggested that the role of the pSTS is related to an initial analysis of social cues to provide a signal of the intention of another individual (Allison, Puce, \& McCarthy, 2000).

\section{Brain Areas Associated With the Value Parameter}

The value parameter of the subjective expected utility model has been examined extensively in relation to neural activation patterns, so a large body of literature relates brain areas to valuing and to subsequently choosing a reward. The brain areas associated most prominently with this parameter are the ventral striatum and the OFC (Sanfey et al., 2006).

The OFC has long been implicated in representation of reward magnitude (e.g., by Knutson \& Cooper, 2005). In addition, the striatal dopamine system - consisting of (most notably) the caudate nucleus, the putamen, and the nucleus accumbens, as well as the dopaminergic projections onto these areas from the substantia nigra and the ventral tegmental area-is thought to process reward magnitude, and thus to be crucially involved in rewardbased decision making (Cromwell \& Schultz, 2003). In particular, the ventral striatum (mostly the nucleus accumbens) has been shown to encode reward magnitude in single-cell recording studies in animals as well as in fMRI studies in humans (e.g., Knutson \& Cooper, 2005; Rolls, 2004). Computations in circuitries involving mainly the ventromedial OFC and ventral striatum play a key role in reward-based reversal learning (Cools, Clark, Owen, \& Robbins, 2002), reflecting the need to update the reward values associated with responses to specific stimuli.

Interestingly, the acquisition of friendship and social approval, which is an important incentive in human social behavior, was found to activate the same ventral striatal reward circuitry as monetary rewards (Güroğlu et al., 2008). Likewise, observing a charity receiving money was found to activate the same striatal reward circuitry as monetary payoffs to oneself (Harbaugh, Mayr, \& Burghart, 2007). These results endorse the notion of a common "neural currency" of reward value, irrespective of whether the reward is monetary or social in nature (see, e.g., Montague \& Berns, 2002).

Although emotional reasoning was not incorporated into early economic decision-making theories, the advent of neuroeconomics has indicated its importance in economic decision making (e.g., Glimcher \& Rustichini, 2004). Emotions can be assumed to be relevant in the valuing of reward outcome. Fairness norms, in particular, play a role in the modulation of social relations (Dawes, Fowler, Johnson, McElreath, \& Smirnov, 2007). In a decision-making context, negative emotional states can be caused by a lack of reciprocity or (feelings of) inequity. A number of brain areas have been implicated in emotional modulations of decision making, such as the OFC, the anterior cingulate cortex (ACC), the amygdala, and the insula (for a review, see van Winden et al., 2008).

The ventromedial OFC has been shown to be important in the affective appraisal of the consequences of one's choices, thus emotionally coloring the assessed reward 
value (Bechara \& Damasio, 2005). The anterior insula has been suggested to encode social interactions in terms of aversion or the unfairness of the other's offer, thus representing the social value of a reward, and to encourage or discourage trust and positive responses (Montague \& Lohrenz, 2007; Sanfey, 2007b). Activation in the anterior insula was greater when participants in the Ultimatum Game were offered unfair instead of fair shares of money; this activation became more pronounced as the unfairness of the offer increased, and interestingly, the stronger the activation of the anterior insula, the higher the probability that the participant would decline the unfair offer (Sanfey, Rilling, Aronson, Nystrom, \& Cohen, 2003). This brain area has also been associated with responses to painful and repulsive stimuli (Calder, Lawrence, \& Young, 2001; Derbyshire et al., 1997) and is thought to map physiological body states (Critchley, Elliott, Mathias, \& Dolan, 2000). This may imply that anterior insula activation labels an unpleasant interaction as physically aversive, and thus serves as a mechanism to avoid future interactions with a certain partner (Sanfey, 2007b).

\section{Neurotransmitter Systems Associated With Economic Decision Making}

In addition to the abovementioned brain areas, specific neurotransmitter systems are hypothesized to be important in economic decision making, most prominently dopamine and serotonin.

The importance of dopamine is evidenced by the wide distribution of its receptors throughout the aforementioned midbrain reward centers. The neurons in the mesolimbic and mesofrontal pathways project from the ventral tegmental area into various limbic areas of the brain (including the nucleus accumbens) and into all frontal brain areas. The neurons in the nigrostriatal pathway project from the substantia nigra into the dorsal striatum. Because of the importance of these midbrain systems in the detection and prediction of rewarding stimuli (Schultz, 2000), it seems plausible that outcome-based economic decision-making tasks depend on the dopaminergic neurotransmitter system. Because of the importance of dopamine in both the dorsal and ventral striatum, the functionality of this neurotransmitter can be tentatively related to either the value parameter or the probability parameter of the subjective expected utility model (cf. Fiorillo, Tobler, \& Schultz, 2003, and Tobler, Fiorillo, \& Schultz, 2005, in which dopamine neurons have been associated with coding reward probability and value, respectively). Moreover, many of the brain circuits involved in reward processing are also innervated by serotonin neurons. Thus, neither dopamine nor serotonin can be assigned unequivocally to one model parameter, although some patterns appear to emerge.

Dopaminergic firing can increase and decrease substantially from its baseline levels to support discrimination between the outcome values of different responses. Transient bursts of activity are elicited initially by unpredicted rewards and, as learning progresses, also by stimuli that predict the delivery of reward; phasic dips of activity (below baseline) occur when an expected reward is not delivered (Holroyd \& Coles, 2002; Pan, Schmidt, Wickens,
\& Hyland, 2005). Such changes in dopaminergic activity in the dorsal striatum correlate with incentive learning (to select decisions leading to positive outcomes) and avoidance learning (to avoid decisions leading to negative consequences; Schultz, 2002). The efficacy of recently active synapses may be reinforced by a burst of extracellular levels of dopamine acting as a teaching signal, serving to strengthen (or learn) rewarding behaviors (Suri, Bargas, \& Arbib, 2001). Phasic bursts of dopamine in the striatum, as elicited by reward, transiently enhance activation in the so-called direct pathway within the basal ganglia, while suppressing activation in the indirect pathway (Frank, Seeberger, \& O'Reilly, 2004). This pattern serves to reinforce the association between the stimulus and the action (represented in premotor cortex) that yielded a reward (incentive learning, or learning to select choices predominantly associated with positive outcomes). Phasic dopamine dips, as elicited by the absence of expected reward, lead to the opposite pattern, serving to trim down the association between the stimulus and the action that failed to yield a reward (avoidance learning, or learning to avoid selecting choices predominantly associated with negative outcomes). Parkinson's patients on dopaminergic medication show deficiencies in avoidance learning, whereas they are proficient in incentive learning. However, this pattern is reversed when the patients are taken off medication: Now they show impaired incentive learning but intact avoidance learning (Frank et al., 2004). Thus, high and low tonic levels of dopamine are associated with incentive learning and avoidance learning, respectively. In this regard, the role of dorsal striatal dopamine in learning to predict which actions enhance the probability of obtaining a reward relate explicitly to the probability parameter of the subjective expected utility model. However, dopaminergic projections into the ventral striatum support reversal learning (Cools et al., 2002), which (as argued above) relates to the value parameter.

The serotonin system also appears to be relevant for economic decision making, although it has been studied considerably less extensively than dopamine. Reductions in serotonin can impair decision making by enhancing the effect of punishment relative to reward (Chamberlain et al., 2006; Cools, Roberts, \& Robbins, 2008). Depletion of the serotonin precursor tryptophan has been found to yield reduced discrimination between the magnitudes of the expected gains associated with different choices. This suggests that serotonin mediates decision making in healthy volunteers by modulating the processing of reward cues (Rogers et al., 2003), perhaps by facilitating the evaluation of future rewards (Schweighofer, Tanaka, \& Doya, 2007), which in turn suggests that serotonin functionality corresponds to the value parameter of the subjective expected utility model. Serotonergic neurons project into the basal ganglia, controlling phasic dopamine release into the striatum, and thereby the time scale of reward prediction, modulating the adequate computation of reward prediction errors (Schweighofer et al., 2007; Tanaka et al., 2004). It therefore seems plausible that serotonin functionality corresponds not only to the value parameter but also to the probability parameter. The latter suggestion re- 
ceives support from a tryptophan depletion study (which serves to reduce serotonin levels and enhance responsiveness to aversive signals) in which tryptophan depletion facilitated the prediction of punishment (Cools, Robinson, \& Sahakian, 2008).

Many of the brain areas, and both of the neurotransmitter systems, mentioned here are susceptible to the effects of aging. This, along with the subsequent effect on decision making, is the focus of the next section.

\section{Economic Decision Making and Neurocognitive Aging}

To describe the effect of aging on economic decision making, a concise overview of the effects of aging on the brain areas associated with economic decision making will first be presented. That subsection serves mainly to create a context for the review of behavioral and neuroimaging findings that follows it in three subsections. The first of these deals with findings related to the probability parameter of the subjective expected utility model, the second describes studies that relate to the value parameter of this model, and the final subsection covers the potential role of dopamine in decision making. Impairments in either (or both) of the parameters due to age-related neurocognitive decline would be expected to lead to less than optimal decision making, because any such effect would render the subjective utility of each given outcome suboptimal. Age-related impairments in the probability parameter might lead to problems with the performance of tasks that capitalize on probabilistic rewarding; agerelated impairments in the value parameter might lead to problems with assessing both the magnitude and the appreciation of a given reward or outcome. In light of the changes in these parameters with age, the final subsection discusses the specific role of dopamine in decision making in some depth.

It should be pointed out once more that no clear-cut definition exists of what constitutes a (neuro)economic decision-making task. Therefore, a variety of tasks that deal with outcome-based decision making and decision learning will be discussed in this section; after all, such tasks require optimal decision-making strategies in order to maximize a reward, and therefore they seem to fit in well with the research goals of neuroeconomics. Terms that are just as hotly debated as the nature of an economic decision-making task are aging, old, and elderly. Naturally, no clear, age-related cutoff scores allow us to designate a person as "old." The ages of participants in the studies we reviewed ranged from the mid-60s to the mid-80s. Obviously, such a range in age across studies is no minor issue and is a well-known problem in aging research. In most of the studies we report here, the old participants were about 60 years of age on average, which should allow for fairly comparable results.

\section{The Effect of Brain Aging on \\ Economic Decision Making}

Aging of the brain is accompanied by atrophy (e.g., through cell shrinkage; Raz et al., 2005) and neuronal loss, both through the process of apoptosis (programmed cell death) and pathology-related necrosis. However, aging does not affect all brain areas to an equal extent (Band, Ridderinkhof, \& Segalowitz, 2002; Grieve, Williams, Paul, Clark, \& Gordon, 2007; Raz, Williamson, Gunning-Dixon, Head, \& Acker, 2000; Woodruff-Pak, 1997). For instance, the insula is known to show a particular vulnerability to the effects of age. Allen, Bruss, Brown, and Damasio (2005) have described that the graymatter volume of this area declines linearly with age, an effect also reported by Good et al. (2001). Interestingly, the elderly have shown extra recruitment of the insula in a motor task used by Heuninckx, Wenderoth, Debaere, Peeters, and Swinnen (2005), possibly as a compensation for age-related decline in functionality. The OFC is also susceptible to age-related deterioration (Resnick, Lamar, \& Driscoll, 2007), although the absolute amount of neuronal loss in this area is not exceptional (Band et al., 2002). Band et al. have also discussed an age-related loss of dopamine receptors in the ACC, which may lead to declined performance in the elderly; in addition, a loss of ACC gray matter in the elderly has been reported (Good et al., 2001). The gray-matter volume of the STS has also been demonstrated to decline, the percentage varying from $12 \%$ in 7 - to 60 -year-olds to $24 \%$ in 40 - to 87 -year-olds (Sowell et al., 2003). Finally, structural age-related decline has been observed in dorsal as well as ventral striatum volumes (Matochik et al., 2000; Raz et al., 2003; Walhovd et al., 2005).

The striatal areas that are relevant in economic decision making are rich in dopamine and serotonin receptors. The number of dopamine receptors is known to decline quite severely in old age, which leads to a cognitive deterioration (see, e.g., Bäckman et al., 2006). The striatum appears to be particularly affected by age (Kaasinen \& Rinne, 2002), but other areas (especially in prefrontal cortex) are affected as well (Kaasinen et al., 2000). Like the dopaminergic neurotransmitter system, the serotonin system is affected by age (Wang et al., 1995), which is particularly evidenced by a decline in the density of serotonin binding sites (Woodruff-Pak, 1997).

These structural age-related changes in the brain are typically accompanied by functional declines in the cognitive processes subserved by the affected neural circuits and neurotransmitter systems (Bäckman et al., 2006; Band et al., 2002; Reuter-Lorenz \& Lustig, 2005). This neurocognitive change is likely to interfere with economic decision making. As reviewed above, the MFC, dorsal striatum, aPCC, and pSTS have all been found to be linked specifically to the probability parameter of the subjective expected utility model, whereas the OFC, ventral striatum, insula, and ACC have been specifically related to the value parameter. Since most of these brain areas are subject to structural age-related decline, one would expect the elderly to have difficulty with correctly assessing both the probability and the value of possible outcomes, which should lead to less-than-optimal decision-making strategies. Furthermore, learning contingencies between actions and outcomes may become more difficult if the dopamine and serotonin systems are affected by age and not functioning optimally. Age-related declines in both of these neuro- 
transmitter systems may have detrimental consequences for either the probability or the value parameter; hence, deterioration of these systems may lead to less-than-optimal decision-making performance by older adults.

In this subsection, a concise overview of the effects of aging on brain areas relevant to decision making was presented. In the next ones, the effects of these age-related changes on economic decision making will be discussed extensively.

\section{Neuroeconomics and Aging: The Probability Parameter}

One decision-making factor indirectly related to the reward probability parameter is conservatism. Popular belief holds that older adults are relatively risk averse: They tend to take fewer risks by choosing safer options (see, e.g., Lee, Leung, Fox, Gao, \& Chan, 2008). This preference was not confirmed, however, in a study by Kovalchik et al. (2005), who reported that seniors did not make more conservative decisions than younger participants did. This issue must await further empirical investigation, because surprisingly few studies have actually addressed the issue of conservativeness in economic decision making (Chou et al., 2007; Deakin et al., 2004; Mather, 2006).

A number of studies have examined changes in probabilistic learning with age on the basis of reward prediction error. Typically, older participants need more trials to reach a learning criterion (see, e.g., Mell et al., 2005; SchmittEliassen, Ferstl, Wiesner, Deuschl, \& Witt, 2007). Documented age-related deficits in learning new stimulusaction-reward associations have been linked explicitly to dorsal striatal dopaminergic declines (Fera et al., 2005; Frank \& Kong, 2008; Nieuwenhuis et al., 2002). Structural age-related reductions in baseline levels of DA may render the transient DA bursts insufficiently powerful to support incentive learning, whereas DA dips serve to amplify avoidance learning by depleting postsynaptic receptors from dopaminergic transmission even further. Thus, as compared with younger adults, who tend to be incentive learners, older adults tend to be avoidance learners (Frank $\&$ Kong, 2008), similar to Parkinson's patients who suffer from striatal DA deficiencies and show deficient incentive learning and amplified avoidance learning (Shohamy et al., 2004).

Other studies on age changes in probabilistic learning make use of varieties of the Iowa gambling task, in which participants have to pick cards from several decks to earn money. Unbeknownst to the participants, one deck contains cards with large gains but, occasionally, huge losses of money; whereas the other deck has lower gains per card, but also smaller occasional losses. In the long run, it is therefore advantageous to select cards from the second deck. Kovalchik et al. (2005) observed that young and old participants alike learned to pick the beneficial deck of cards and that it did not take the elderly significantly longer to learn this. The effect of aging on Iowa gambling task performance is under debate, however. Some studies (e.g., Wood, Busemeyer, Koling, Davis, \& Cox, 2005) have shown that the elderly are capable of performing just as well on this task as younger participants but sim- ply use different strategies, and other studies (Kovalchik et al., 2005; Lamar \& Resnick, 2004; Stout, Rodawalt, $\&$ Siemers, 2001) have indicated that the elderly do not perform differently from younger participants at all. On the other hand, age-related errors of perseveration have also been reported: Instead of learning to pick cards from advantageous decks, the elderly (as opposed to middleaged and young participants) equally often kept choosing cards from both types of deck (Fein, McGillivray, \& Finn, 2007; Isella et al., 2008; MacPherson, Philips, \& Della Sala, 2002). Another study (Denburg, Bechara, \& Damasio, 2005) indicated that only a subgroup of elderly did not learn to pick the advantageous deck at all, which demonstrates the heterogeneity of the elderly as a group of participants (we will come back to this point in the Conclusion). Furthermore, Denburg, Recknor, Bechara, and Tranel (2006) reported that the nonimpaired group showed a higher anticipatory skin conductance reactivity for advantageous decks, which suggests that the anticipation of positive outcomes might lead to more optimal decision making in older adults.

Taken together, although studies using varieties of the Iowa gambling task have yielded mixed results, a few of these reports do seem to point to age-related impairment in the probability parameter. Problems of this kind, generally speaking, would lead to less-than-optimal decisionmaking strategies, resulting, for instance, in difficulties in learning to avoid bad decks. Note, however, that this task to some extent entails reversal learning, which is associated with the value rather than the probability parameter. Participants will likely start off by choosing cards from a bad deck, because this deck leads to high rewards. After a number of trials, the participants are expected to understand that these high rewards are nullified by severe punishments (i.e., losing a large sum of money). This experience should be incorporated into the representation that the participants have formed of the bad decks, thereby altering the initial representation of those decks.

Studies of age changes in multiplayer interactions, in which the probability of a positive outcome is to be predicted or assessed on the basis of other players' behavior, have thus far been scarce. One study in which participants in different age groups played the trust game with other participants from the same age group reported that trust remained unaltered across the adult life span (Sutter \& Kocher, 2007). Although theory of mind may be subject to some age-related decline (Slessor, Phillips, \& Bull, 2007), no age differences are observed when participants have to take the strategies of other players into account to maximize their own gain in the $p$-beauty contest task (Kovalchik et al., 2005).

Summary. As reviewed above, the MFC, dorsal striatum and its dopaminergic innervations, aPCC, and pSTS have been found to be linked specifically to the probability parameter of the subjective expected utility model. Although few neuroimaging studies have been reported that examine effects of aging on functional activation of these areas in the context of economic decision making, a number of behavioral and neurocomputational studies and one fMRI study (Fera et al., 2005) begin to shed light on 
the degree to which the probability parameter is susceptible to the effects of aging. A twofold pattern emerges. First, studies that have examined age changes in probabilistic learning of stimulus-action-reward associations on the basis of reward prediction error have consistently documented age-related deficits, which were found to be linked explicitly to dorsal striatal dopaminergic declines. Second, by contrast, investigations of age changes in probabilistic learning in varieties of the Iowa gambling task have yielded a less consistent picture, with some studies reporting age-related impairments and others reporting age equivalence. Studies of conservatism and risk aversion also do not ubiquitously report that older adults prefer safer options (with greater probabilities of smaller rewards). Behavioral studies with the trust game and other tasks in which the probability of positive outcome is to be predicted or assessed on the basis of other players' behavior, associated with activation of the aPCC and pSTS, also report no age differences in maximizing gain by assessing other players' strategies.

Thus, although studies of elementary probabilistic learning do suggest age effects on the probability parameter, such effects cannot be confirmed unequivocally in more complex economic decision-making tasks. The effects of aging on the value parameter are the next topic.

\section{Neuroeconomics and Aging: The Value Parameter}

In an fMRI study using a card-guessing task that rewarded correct and incorrect guesses with (respectively) monetary gains and losses, the striatal signaling of outcome value did not differ between young and older participants (Cox, Aizenstein, \& Fiez, 2008). Activation in the ventral caudate showed reliable differentiation between rewards and punishments for young and old alike, even though the magnitude and extent of striatal activation were slightly reduced among seniors. Several other neuroimaging studies with young and older adults have compared outcome valuation during reward delivery with reward value anticipation (prior to reward delivery, participants viewed different cues that indicated whether money could be lost or won), using the monetary incentive delay task introduced by Knutson, Westdorp, Kaiser, and Hommer (2000). In one fMRI study, the elderly generally responded more slowly and made more errors than the young control group (Schott et al., 2007). During reward value anticipation, the young participants showed activation in the insula and ACC as well as in the ventral striatum; the ventral striatal activation had vanished by the time of actual reward delivery (money was won if a response was fast enough). Older participants showed the opposite pattern: Ventral striatal activation was not present during reward value anticipation and remained absent until actual reward delivery. A similar study compared the anticipation of gains with the anticipation of losses (Samanez-Larkin et al., 2007). Both young and old participants activated the ventral striatum and anterior insula during gain anticipation, whereas during loss anticipation, young but not older participants showed activation of the anterior insula. Although it is not evident a priori whether changes in BOLD activation reflect changes in processing efficiency or in strategy (or both; cf. Mata, Schooler, \& Rieskamp, 2007), this pattern may be taken as evidence for a positivity bias often associated with aging (cf. Carstensen, 1992; Mather, 2006).

Support for such a bias was reported by Leclerc and Kensinger (2008), who found a differentiation in activation in the ventromedial OFC. In their task, participants had to observe positive and negative (emotionally charged) as well as neutral images. The results indicated that the ventromedial OFC was activated more strongly by negative than by positive images in young participants, but this pattern was reversed in the elderly. According to these authors, this activation reversal may be the basis for the positivity bias often reported in elderly participants (although a recent meta-analysis by Ruffman, Henry, Livingstone, \& Philips [2008] stated that this positivity effect is quite complex: Under certain circumstances, the elderly do not appear to avoid negative stimuli). In the context of the findings of Samanez-Larkin et al. (2007), it would be interesting to test the possibility that such a bias influences the elderly, perhaps by having these participants perform an additional test in which they, for instance, have to remember positive and negative stimuli.

Together, these studies suggest that the elderly adequately recruit the ventral striatum to represent the value of rewards but have more trouble activating it to represent reward value in anticipation of such rewards. In terms of the subjective expected utility model, these findings correspond to minor age-related impairments in the value parameter of the model. Such an impairment could be expected to lead to less-than-optimal economic decision making and might be related to failure to (sufficiently) recruit the ventral striatum. Inadequate representation of reward value might account also for the problems that older adults experience with learning from feedback. If the ventral striatum is not sufficiently recruited in encoding the value of feedback, feedback might then not result in optimal decision making - at the very least, the elderly might need more feedback and, subsequently, more trials to improve their performance.

The latter pattern was reported by Mell et al. (2005), who used a probabilistic object reversal learning task, with a stochastic payoff schedule, in which the participants had to maximize a reward. A learning criterion was established, and once the participants reached this, the reward schedule was altered. The results indicated that not only did the elderly score fewer points than the younger participants, but they also needed more trials to reach the learning criterion. These results fit in with behavioral data indicating that older participants are less efficient than young participants at reversal learning (Chasseigne et al., 2004; Weiler, Bellebaum, \& Daum, 2008; see also Tsuchida, Kubo, \& Kojima, 2002).

Summary. As reviewed above, the OFC, ventral striatum, insula, and ACC have been found to be linked specifically to the value parameter of the subjective expected utility model. A number of behavioral and neuroimaging studies have examined the effects of aging on the functional activation of these areas in the context of economic decision making. First, fMRI studies that have examined 
the neural representation of reward value have suggested that the elderly adequately recruit the ventral striatum to represent the value of rewards but have trouble activating this area to represent reward value in anticipation of such rewards. Recruitment of the insula and ACC in reward anticipation has not been found to differ among age groups. Second, several behavioral studies have reported age-related impairments in reversal learning, typically associated with $\mathrm{OFC}$ and ventral striatum, but neuroimaging studies to confirm hypoactivation of these structures are still lacking. In terms of the subjective expected utility model, these combined findings suggest moderate impairments in the value parameter of the model. We next turn to the role of dopamine in neuroeconomic decision making.

\section{Neuroeconomics and Aging: The Roles of Dopamine and Serotonin}

Mell et al. (2005) linked their behavioral data to neurological findings. The frontal cortex, basal ganglia, and midbrain dopamine system are implied to be important in the detection and prediction of rewarding stimuli (Schultz, 2000). The number of dopamine receptors in the striatum is known to decline with age, the result of which may be a cognitive deterioration caused by less efficient information processing in the functional brain circuitries that subserve - among other functions - reward processing (Bäckman et al., 2006), which leads to less effective decision making. According to a model by Braver and Barch (2002), the dorsolateral prefrontal cortex (DLPFC) may perform a "gating" function that biases what information is processed. This too might explain the decline in task performance among the elderly: If reward representations are monitored in the DLPFC, and age-related dopamine decline negatively biases the information processed by this brain area, task performance may deteriorate (see also Frank \& Kong, 2008).

Successful reward-based decision making depends mainly on a reward system that includes dopamine projections from the ventral tegmental area to the ventral striatum, prefrontal cortex, and amygdala (Marschner et al., 2005). Both the dopamine and the serotonin systems are known to be affected by age (see, e.g., Wang et al., 1995), which is characterized by receptor loss in both the striatum and the prefrontal cortex; age-related structural decline has also been reported, for instance in the frontal cortex (e.g., Grieve et al., 2007). Grieve et al. hypothesized that these functional and structural changes of the reward system lead to a loss of behavioral flexibility, and therefore a decline in performance on rewardbased decision-making tasks by the elderly. Although a number of tasks (e.g., the Wisconsin card sorting task and Rogers's task) have displayed age differences in performance, other tasks (e.g., the Iowa gambling task) have indicated less consistent age-related patterns. According to Mell et al. (2005), the elderly can learn to make correct stimulus-response associations, and even adapt them flexibly to new situations; the elderly just need more effort to accomplish this than do younger individuals. Both structural and functional changes may underlie this effect. For instance, a decline in dopamine efficiency may lead to an increased signal-to-noise ratio (cf. Li, Lindenberger, \& Sikström, 2001), which would account for the increased effort it takes the elderly to learn reward-based associations.

According to Li, Biele, Mohr, and Heekeren (2007), neurotransmitter systems are essential for many (economic) decision-making processes: Dopamine, for instance, has been found to be crucial for reward-based learning. Right after receiving a reward or a rewardpredicting stimulus, midbrain dopamine neurons show phasic activations (Schultz, Dayan, \& Montague, 1997). A number of models have been developed in which dopaminergic reward signaling is quantified as a reward prediction error (i.e., the discrepancy between expected and received awards); these models can be utilized to describe the effect of age-related dopamine decline on the deterioration of cognitive functions (e.g., Nieuwenhuis et al., 2002). A model by Li et al. (2007; Li et al., 2001) simulates age-related dopamine neuromodulation by attenuating "gain control of the sigmoidal activation function that models presynaptic to postsynaptic input-response transfer" (Li et al., 2007, p. 105). The result of a reduced slope of this sigmoidal function, due to attenuated gain modulation, is an increase in random activation (which corresponds to randomly firing dopamine neurons). This simulation of age produces increased variability in the performance of the "aged" networks. Such a model is useful in understanding impaired performance of the elderly in decision-making tasks that are dependent on the dopaminergic system.

Despite the fact that some studies have documented a role for serotonin in economic decision making, to our knowledge no studies have examined the effects of normal aging on this serotonergic modulation.

Summary. As reviewed above, the functionality of the neurotransmitters dopamine and serotonin can be tentatively related to either the probability parameter or the value parameter of the subjective expected utility model. The role of dorsal striatal dopamine in learning to predict which actions enhance the probability of obtaining a reward relate explicitly to the probability parameter, whereas dopaminergic projections into the ventral striatum support reversal learning that relates to the value parameter. The generally reported decline of dopamine receptors throughout the striatum (dorsal as well as ventral) as well as in various parts of frontal cortex may thus affect either parameter. The role of serotonin in controlling phasic dopamine release into the striatum, thereby modulating the computation of reward prediction errors, suggests that serotonin functionality corresponds to the probability parameter, whereas the role of serotonin in enhancing the effect of punishment relative to reward and in discriminating between magnitudes of expected gains suggests that serotonin functionality corresponds to the value parameter. Age-related declines in striatal serotonergic modulation again may affect either of the model parameters. 


\section{The Future of Aging and Neuroeconomics: Where to Go and What to Beware Of}

The emerging patterns that derive from the reviews of economic decision-making studies with elderly participants in the preceding section generate important insights, but also expose hiatuses and caveats in this relatively young field of research. Much work remains to be done in the neuroeconomics of aging. In this section, a few avenues that seem promising will be discussed, as well as a number of caveats that should be considered while conducting decision-making research with older adults.

\section{Promising Lines of Investigation}

Although the subjective expected utility model is representative of a class of widely considered models, all capitalizing in one way or another on the combined factors of reward value (most often in terms of reward magnitude) and reward probability, there are of course alternative conceptualizations of decision making. One representative example is provided by Rangel, Camerer, and Montague (2008), who describe a model that consists of five modules: representation (of internal and external states, as well as appropriate actions), valuation (comparable to the value parameter of the subjective expected utility model), action selection (choosing an appropriate response on the basis of valuation of the possible outcomes), outcome evaluation (how desirable were the outcomes of the choice?), and finally long-term learning. In a similar vein, Doya (2008) presents a number of formal mathematical operationalizations of factors associated with decision making (e.g., the value of a given reward), linking neurotransmitter systems and brain circuits to these computational factors. In the present report, rather than expressing a strong preference for one (class of) model over another, we have selected the subjective expected utility model as a descriptive framework because of its parsimonious and transparent makeup, its generic representation of a wider class of models, its well-charted links with neural activation patterns, and its straightforward utility in illustrating, reviewing, and appraising the literature on age changes in economic decision making.

As is clear from the review above, neuroimaging studies of age changes in economic decision making have been devoted more to the value parameter than to the probability parameter of the subjective expected utility model. It would therefore be interesting to direct attention to studying the probability parameter in order to relate it more tightly to the activation of certain brain areas. Knutson et al. (2005) started an interesting line of research into this parameter, and a corroboration of their findings would be useful and informative. Studies of such a kind should focus on the participant's assessment of the probability of a given rewarding outcome and should aim at finding activity in the nucleus accumbens and the ventromedial prefrontal cortex (cf. Knutson et al., 2005).

Furthermore, it would be interesting to study "old-old" seniors. Most of the studies reviewed here tested participants with a mean age of about 60 to 65 . Although these seniors might show age-related differences as compared with younger participants, adding older elderly (say, people well into their 70s or 80s) might add a wealth of information. An adult life span approach (which is taken by, e.g., Juncos-Rabadán, Pereiro, \& Facal, 2008, in a study focusing on response inhibition) would be informative, since this would demonstrate not only whether decisionmaking capacity changes with age, but also the extent to which it changes, and when. It would therefore be interesting to test a large sample of participants, ranging in age from 20 through 80 . Even more useful insights might be obtained from long-range longitudinal studies. Granted, such studies are costly, but the costs should be weighed against the potential contribution of studies of this kind.

Finally, it should be stressed again that neuroeconomics can contribute significantly to our knowledge of decision making by using ecologically valid tasks. We therefore recommend investing time in designing paradigms of a more realistic kind than standard laboratory tasks. Such tasks may allow for drawing more solid conclusions about "real-life," as opposed to laboratory-task, decision making. It is difficult to come up with realistic tasks, but some of the studies reviewed above provide representative examples. For instance, the $p$-beauty contest task used by Kovalchik et al. (2005) is both simple and quite realistic, to the extent that participants need to think about the strategies of other players (whether real or simulated ones) to maximize their own gain. Granted, even this task is slightly artificial, but it exceeds the level of simple buttonpressing whenever a stimulus appears on a computer screen.

In all cases, studying an elderly population requires that the researcher be aware of certain variables that do not play a part in research with younger participants. This is the focus of the next subsection.

\section{Caveats and Issues Associated With Aging and Decision-Making Research}

Although interesting and topical, aging research is characterized by a number of caveats that should be taken into account when conducting studies with older adults. Some general issues, such as problems with comparing the task performance of the elderly with that of younger participants (with all of the associated problems, such as differences between the age groups in motivation or different strategies used to approach a task) or apprehension of the elderly at being "tested," may have played a part in the studies reviewed here and may underlie the apparent lack of consistent findings. The goal of this article is not to give an exhaustive review of such confounds, pitfalls, and traps, but nonetheless, a concise summary of some of the specific variables is in order. For the convenience of the reader, the following information is divided into two subsections: The first describes some conceptual issues for this particular line of research, and the second presents a number of methodological issues.

Conceptual issues of aging and decision-making research. A first problem associated with economic decision-making research concerns the use of real money as a reward in tasks. Rewarding participants with symbolic payoffs (such as points or fictional money) may threaten 
the realism of economic decision-making tasks, because participants may be less motivated when they know that they are not contending for real money. On the other hand, money is not equally important to all participants, which is especially relevant in aging research: Losing a $\$ 5$ reward may not be experienced as a particularly large problem by the elderly, but a student control group may be quite affected by losing that amount. Apart from using points or fictional money instead of real currency, such a problem may be circumvented by using a parametrically determined reward system (as used by, e.g., Samanez-Larkin et al., 2007), in which the absolute amounts of rewards are not compared directly, but instead the patterns of parametrical reward effects are compared.

Next, in light of the findings by Samanez-Larkin et al. (2007), it seems useful to take a possible positivity bias among the elderly into account. After all, as these authors suggested, such a bias might indicate that the elderly avoid risks (because of the negativity associated with risk taking; see Chou et al., 2007). For instance, Frank and Kong (2008) used a probabilistic learning task in which participants had to select one Japanese character from cards containing two such characters. They had to learn to select certain characters in favor of all others (incentive learning), but also to avoid certain other characters (avoidance learning). Older seniors (mean age 77) showed enhanced avoidance learning relative to incentive learning, but younger seniors (mean age 67) did not. Clearly, reservations in taking risks will interfere with task performance that requires risk taking to maximize reward. This is especially relevant, considering that some studies have indicated that the elderly prefer to refrain from making choices at all (for a review, consult Mather, 2006).

A further issue to take into account is that of motivation. Many universities require students to partake in research for course credit, which may lead young control participants to experience task participation as an obligation. It stands to reason that this will reflect on the participants' motivation. On the other hand, many elderly participants are keen to participate in research, for various reasons (see the next paragraph). Generally speaking — on the basis of impressions from our lab - many elderly participants are highly motivated and want to perform as well as they possibly can. Naturally, this contrast presents a problem in research that hinges on maximizing one's reward: Elderly participants may do anything to perform well, and their intrinsic motivation may not compare well with the relatively more extrinsic motivation of younger participants whose concern is to obtain course credit. Obviously, there is no clear-cut solution to this problem, but keeping it in mind when conducting aging research seems useful. A minimal check could entail presenting all participants with an exit questionnaire that ascertains their level of seriousness in participating and to use this data as a covariate in the analysis of the study.

Neuronal loss in the DLPFC may lead to less efficient top-down guidance, which, in turn, may interfere with effective economic decision making when several alternative options need to be considered in relation to current goals and intentions. With regard to the subjective expected utility model, this would imply that the utility of a given outcome would be calculated less efficiently by older adults. For instance, since the elderly needed more trials to learn the new reward association in the Mell et al. (2005) study, the monitoring of previous choices and outcome processing may be affected by age. An age-related reduction in working memory capacity may underlie this decline. Such a working memory deterioration has been linked to reduced functionality of, for instance, the DLPFC (ReuterLorenz, 2002), an area that is implied to be important for the monitoring of items in working memory (Curtis \& D'Esposito, 2003). Such a decline may account for the worse performance of the elderly on a task that requires intact monitoring skills. This generic age-related working memory decline might affect economic decision making in ways beyond specific effects on the probability or the value parameter of the subjective expected utility model.

Methodological issues of aging and decisionmaking research. In addition to obvious caveats, such as the clarity (regarding both the content and the layout) of task instructions and the reduced stamina of older adults, scientists undertaking aging research should beware of some specific challenges. For instance, the elderly population is characterized by a strong heterogeneity. Whereas students as (control) participants may be taken to be fairly homogeneous in such respects as intelligence, reaction time, years of education, and so on, older participants are not. This problem cannot just be ignored, because it interferes quite strongly with interpreting the results of aging studies: Not only may older adults perform significantly differently from younger participants, but there may be extensive differences among seniors as well (in reaction time, number of errors, learning curve, and so on). These individual differences are typically reflected in error variance, which works against interpretable research outcomes. This effect is found not only in behavioral studies, but in neuroimaging work as well. One solution to this problem, in the case of neuroimaging, is the use of socalled covariance-based analysis strategies, which capitalize on individual differences, utilizing them to establish the extent to which brain structures covary in their activation with the efficiency of specific cognitive processes (an approach used successfully by, e.g., Forstmann et al., 2008).

In relation to this point, as Marschner et al. (2005) argued, the aging brain differs considerably from that of the young, in both structural and functional aspects. Of course, one of the main objectives of neuroeconomics research is to find out whether-and if so, how-such differences are reflected in decision making. But if, as Mell et al. (2005) suggested, these neurological changes result in the elderly needing to make more effort to perform a task well, this must be taken into account in research. This can be done by granting the elderly a longer time to respond or more training trials, or by accounting for such additional effort in a quantitative way. Furthermore, since the working memory of the elderly is known to be affected by age (see, e.g., Zacks, Radvansky, \& Hasher, 
1996), their effort may be reduced by using or developing a task that taxes the working memory as little as possible. For instance, the $p$-beauty contest task used by Kovalchik et al. (2005) is in itself reasonably simple, although it does suggest that participants can use quite complicated forms of reasoning - which may be difficult if working memory is loaded with complex task goals.

\section{Summary, Conclusions, and Implications}

The influence of aging on economic decision making is not unequivocally established. Yet a number of behavioral, neuroimaging, and neurocomputational studies have begun to make headway in understanding how the probability and value parameters of the subjective expected utility model are modulated by age. First, elementary processes of probabilistic learning of stimulus-actionreward associations are subject to age-related decline, whereas probabilistic learning in more complex economic decision-making tasks is less consistently associated with age changes. These patterns suggest mild effects of age on the probability parameter, linked mostly to dorsal striatal declines. Second, older adults appear adequate in assessing the value of rewards but show deviant processing in anticipation of such rewards and impairments in reversal learning. These patterns suggest more substantial, but still moderate, effects of age on the value parameter, associated mostly with hypoactivation of the ventral striatum.

Thus, aging appears to exert modulatory effects on the value and (to a lesser extent) probability parameters of the subjective expected utility model, which may lead to lessthan-optimal calculation of the utility of a given outcome. Such a deterioration may not have led to deteriorated task performance in all of the studies reviewed above-but the performance of the older adults in general was altered when compared with that of the younger participants. Furthermore, there appears to be consensus on the role of dopamine: Age-related deterioration of the dopamine system reflects a declined efficiency in reward-based decision making, although it is not clear whether this effect is mediated by the value parameter, the probability parameter, or both. According to Li et al. (2001), a dopamine decline leads to alterations in the neuronal signal-to-noise ratio, which is expressed by more neuronal noise-making it more difficult, for instance, to evaluate the risk associated with different options in a decision-making task.

The subjective expected utility model provides a useful overarching description of the neurocognitive processes involved in economic decision making and outcome-based decision learning and helps us both understand age-related deficiencies in these processes and relate the deficiencies to age changes in the brain. Structural brain changes caused by factors such as neuronal atrophy and reductions in connectivity as well as age-related alterations in neurotransmitter systems (most notably the dopamine system) may underlie the observed age-related changes in the probability and value parameters, for instance by increasing the neuronal noise-to-signal ratio, which leads to less efficient information processing, especially in the brain areas important in subserving economic decision making.
As argued previously, the aging population is characterized to a large extent by heterogeneity. These individual differences may underlie the lack of robustness in aging effects: Therefore, we again recommend testing old-old as well as young-old seniors and, in neuroimaging studies, using a covariance-based analysis approach. Such an approach can capitalize on individual differences and is expected to lead to establishing more robust aging effects.

To conclude, the field of neuroeconomics is young, and the study of neuroeconomics and aging even more sotherefore, much work remains to be done. However, this line of study combines three disciplines (neuroscience, psychology, and economics) and uses ecologically valid tasks that map well onto real-life decisions, leading to interesting insights, and this is a powerful reason to invest effort in this rapidly developing area of research.

\section{AUTHOR NOTE}

This research was supported by a VICI Grant from the Netherlands Organization for Scientific Research to K.R.R. We gratefully acknowledge helpful comments by Helga Harsay on a previous draft. Correspondence can be addressed to K. R. Ridderinkhof, Department of Psychology, University of Amsterdam, Roetersstraat 15, 1018 WB Amsterdam, The Netherlands (e-mail: k.r.ridderinkhof@uva.nl).

\section{REFERENCES}

Allen, J. S., Bruss, J., Brown, C. K., \& Damasio, H. (2005). Methods for studying the aging brain: Volumetric analyses versus VBM. Neurobiology of Aging, 26, 1275-1278. doi:10.1016/j .neurobiolaging.2005.05.017

Allison, T., Puce, A., \& McCarthy, G. (2000). Social perception from visual cues: Role of the STS region. Trends in Cognitive Sciences, 4 , 267-278. doi:10.1016/S1364-6613(00)01501-1

Amodio, D. M., \& Frith, C. D. (2006). Meeting of minds: The medial frontal cortex and social cognition. Nature Reviews Neuroscience, 7 , 268-277.

Bäckman, L., Nyberg, L., Lindenberger, U., Li, S.-C., \& Farde, L. (2006). The correlative triad among aging, dopamine, and cognition: Current status and future prospects. Neuroscience \& Biobehavioral Reviews, 30, 791-807. doi:10.1016/j.neubiorev.2006.06.005

Balleine, B. W., Delgado, M. R., \& Hikosaka, O. (2007). The role of the dorsal striatum in reward and decision-making. Journal of Neuroscience, 27, 8161-8165. doi:10.1523/JNEUROSCI.1554-07.2007

Band, G. P. H., Ridderinkhof, K. R., \& Segalowitz, S. (2002). Explaining neurocognitive aging: Is one factor enough? Brain \& Cognition, 49, 259-267. doi:10.1006/brcg.2001.1499

Baron-Cohen, S., Ring, H. A., Wheelwright, S., Bullmore, E. T., Brammer, M. J., Simmons, A., \& Williams, S. C. R. (1999). Social intelligence in the normal and autistic brain: An fMRI study. European Journal of Neuroscience, 11, 1891-1898.

Bechara, A., \& Damasio, A. R. (2005). The somatic marker hypothesis: A neural theory of economic decision. Games \& Economic Behavior, 52, 336-372. doi:10.1016/j.geb.2004.06.010

Bechara, A., Damasio, A. R., Damasio, H., \& Anderson, S. W. (1994). Insensitivity to future consequences following damage to human prefrontal cortex. Cognition, 50, 7-15. doi:10.1016/0010 -0277(94)90018-3

Bhatt, M., \& Camerer, C. F. (2005). Self-referential thinking and equilibrium as states of mind in games: fMRI evidence. Games \& Economic Behavior, 52, 424-459. doi:10.1016/j.geb.2005.03.007

Braver, T. S., \& BARCH, D. M. (2002). A theory of cognitive control, ageing cognition, and neuromodulation. Neuroscience \& Biobehavioral Reviews, 26, 809-817.

Brunet, E., Sarfati, Y., Hardy-Baylé, M.-C., \& Decety, J. (2000). PET investigation of the attribution of intentions with a nonverbal task. NeuroImage, 11, 157-166. doi:10.1006/nimg.1999.0525

Calder, A. J., Lawrence, A. D., \& Young, A. W. (2001). Neuro- 
psychology of fear and loathing. Nature Reviews Neuroscience, 2, 352-363.

Carstensen, L. L. (1992). Social and emotional patterns in adulthood: Support for socioemotional selectivity theory. Psychology \& Aging, 7, 331-338.

Castelli, F., Happé, F., Frith, U., \& Frith, C. (2000). Movement and mind: A functional imaging of perception and interpretation of complex intentional movement patterns. NeuroImage, 12, 314-325. doi:10.1006/nimg.2000.0612

Chamberlain, S. R., Müller, U., Blackwell, A. D., Clark, L., RobBINS, T. W., \& SAHAKIAN, B. J. (2006). Neurochemical modulation of response inhibition and probabilistic learning in humans. Science, 311, 861-863. doi:10.1126/science. 1121218

Chasseigne, G., Ligneau, C., Grau, S., Le Gall, A., Roque, M., \& Mullet, E. (2004). Aging and probabilistic learning in single- and multiple-cue tasks. Experimental Aging Research, 30, 23-45.

Chou, K.-L., Lee, T. M. C., \& Ho, A. H. Y. (2007). Does mood state change risk taking tendency in older adults? Psychology \& Aging, 22, 310-318. doi:10.1037/0882-7974.22.2.310

Cools, R., Clark, L., Owen, A. M., \& Robbins, T. W. (2002). Defining the neural mechanisms of probabilistic reversal learning using eventrelated functional magnetic resonance imaging. Journal of Neuroscience, 22, 4563-4567.

Cools, R., Roberts, A. C., \& Robbins, T. W. (2008). Serotoninergic regulation of emotional and behavioural control processes. Trends in Cognitive Sciences, 12, 31-40. doi:10.1016/j.tics.2007.10.011

Cools, R., Robinson, O. J., \& Sahakian, B. (2008). Acute tryptophan depletion in healthy volunteers enhances punishment prediction but does not affect reward prediction. Neuropsychopharmacology, 33, 2291-2299. doi:10.1038/sj.npp.1301598

Cox, K. M., Aizenstein, H. J., \& Fiez, J. A. (2008). Striatal outcome processing in healthy aging. Cognitive, Affective, \& Behavioral Neuroscience, 8, 304-317. doi:10.3758/CABN.8.3.304

Critchley, H. D., Elliott, R., Mathias, C. J., \& Dolan, R. J. (2000). Neural activity relating to generation of galvanic skin conductance responses: A functional magnetic resonance imaging study. Journal of Neuroscience, 20, 3033-3040.

Cromwell, H. C., \& Schultz, W. (2003). Effects of expectations for different reward magnitudes on neuronal activity in primate striatum. Journal of Neurophysiology, 89, 2823-2838. doi:10.1152/ jn.01014.2002

Curtis, C. E., \& D'Esposito, M. (2003). Persistent activity in the prefrontal cortex during working memory. Trends in Cognitive Sciences, 7, 415-423. doi:10.1016/S1364-6613(03)00197-9

Dawes, C. T., Fowler, J. H., Johnson, T., McElreath, R., \& Smirnov, O. (2007). Egalitarian motives in humans. Nature, 446, 794-796. doi:10.1038/nature05651

Deakin, J., Aitken, M., Robbins, T., \& Sahakian, B. J. (2004). Risk taking during decision-making in normal volunteers changes with age. Journal of the International Neuropsychological Society, 10, 590-598. doi:10.1017/S1355617704104104

Delgado, M. R., Frank, R. H., \& Phelps, E. A. (2005). Perceptions of moral character modulate the neural systems of reward during the trust game. Nature Neuroscience, 8, 1611-1618. doi:10.1038/nn1575

Denburg, N. L., Bechara, A., \& Damasio, A. R. (2005). The ability to decide advantageously declines prematurely in some normal older persons. Neuropsychologia, 43, 1099-1106. doi:10.1016/j .neuropsychologia.2004.09.012

Denburg, N. L., Cole, C. A., Hernandez, M., Yamada, T. H., Tranel, D., Bechara, A., \& Wallace, R. B. (2007). The orbitofrontal cortex, real-world decision-making, and normal aging. Annals of the New York Academy of Sciences, 1121, 480-498. doi:10.1196/ annals.1401.031

Denburg, N. L., Recknor, E. C., Bechara, A., \& Tranel, D. (2006). Psychophysiological anticipation of positive outcomes promotes advantageous decision-making in normal older persons. International Journal of Psychophysiology, 61, 19-25. doi:10.1016/j .ijpsycho.2005.10.021

Derbyshire, S. W. G., Jones, A. K. P., Gyulai, F., Clark, S., Townsend, D., \& Firestone, L. L. (1997). Pain processing during three levels of noxious stimulation produces differential patterns of central activity. Pain, 73, 431-445.
Doya, K. (2008). Modulators of decision-making. Nature Neuroscience, 11, 410-416.

Fein, G., McGillivray, S., \& Finn, P. (2007). Older adults make less advantageous decisions than younger adults: Cognitive and psychological correlates. Journal of the International Neuropsychological Society, 13, 480-489. doi:10.1017/S135561770707052X

Fera, F., Weickert, T. W., Goldberg, T. E., Tessitore, A., Hariri, A., DAS, S., ET AL. (2005). Neural mechanisms underlying probabilistic category learning in normal aging. Journal of Neuroscience, 25, 11340-11348. doi:10.1523/JNEUROSCI.2736-05.2005

Fiorillo, C. D., Tobler, P. N., \& Schultz, W. (2003). Discrete coding of reward probability and uncertainty by dopamine neurons. Science, 299, 1898-1902. doi:10.1126/science.1077349

Forstmann, B. U., Jahfari, S., Scholte, H. S., Wolfensteller, U., VAN DEN Wildenberg, W. P. M., \& RidderinkHof, K. R. (2008). Function and structure of the right inferior frontal cortex predict individual differences in response inhibition: A model-based approach. Journal of Neuroscience, 28, 9790-9796. doi:10.1523/ JNEUROSCI.1465-08.2008

Frank, M. J., \& Kong, L. (2008). Learning to avoid in older age. Psychology \& Aging, 23, 392-398. doi:10.1037/0882-7974.23.2.392

FranK, M. J., \& O'ReILly, R. C. (2006). A mechanistic account of striatal dopamine function in human cognition: Psychopharmalogical with cabergoline and haloperidol. Behavioral Neuroscience, 120, 497517. doi:10.1037/0735-7044.120.3.497

Frank, M. J., Seeberger, L. C., \& O'Reilly, R. C. (2004). By carrot or by stick: Cognitive reinforcement learning in Parkinsonism. Science, 306, 1940-1943. doi:10.1126/science. 1102941

Gallagher, H. L., \& Frith, C. D. (2002). Functional imaging of "theory of mind." Trends in Cognitive Sciences, 7, 77-83.

Gallagher, H. L., Happé, F., Brunswick, N., Fletcher, P. C., Frith, U., \& Frith, C. D. (2000). Reading the mind in cartoons and stories: An fMRI study of "theory of the mind" in verbal and nonverbal tasks. Neuropsychologia, 38, 11-21. doi:10.1016/S0028 -3932(99)00053-6

Glimcher, P. W., \& Rustichini, A. (2004). Neuroeconomics: The consilience of brain and decision. Science, 306, 447-452.

Good, C. D., Johnsrude, I. S., Ashburner, J., Henson, R. N. A., Friston, K. J., \& Frackowiak, R. S. J. (2001). A voxel-based morphometric study of ageing in 465 normal adult human brains. NeuroImage, 14, 21-36. doi:10.1006/nimg.2001.0786

Grieve, S. M., Williams, L. M., Paul, R. H., Clark, C. R., \& GorDON, E. (2007). Cognitive aging, executive function, and fractional anisotropy: A diffusion tensor MR imaging study. American Journal of Neuroradiology, 28, 226-235.

GüroĞlu, B., Haselager, G. J. T., van Lieshout, C. F. M., Takashima, A., RijpKema, M., \& Fernández, G. (2008). Why are friends special? Implementing a social interaction simulation task to probe the neural correlates of friendship. NeuroImage, 39, 903-910. doi:10.1016/j.neuroimage.2007.09.007

Harbaugh, W. T., Mayr, U., \& Burghart, D. R. (2007). Neural responses to taxation and voluntary giving reveal motives for charitable donations. Science, 316, 1622-1625. doi:10.1126/science. 1140738

Haruno, M., \& Kawato, M. (2006). Different neural correlates of reward expectation and reward expectation error in the putamen and caudate nucleus during stimulus-action-reward association learning. Journal of Neurophysiology, 95, 948-959. doi:10.1152/jn.00382.2005

Heuninckx, S., Wenderoth, N., Debaere, F., Peeters, R., \& SwinNEN, S. P. (2005). Neural basis of aging: The penetration of cognition into action control. Journal of Neuroscience, 25, 6787-6796. doi:10.1523/JNEUROSCI.1263-05.2005

Hikosaka, O., Bromberg-Martin, E., Hong, S., \& Matsumoto, M. (2008). New insights on the subcortical representation of reward. Current Opinion in Neurobiology, 18, 203-208. doi:10.1016/j .conb.2008.07.002

Holroyd, C. B., \& Coles, M. G. H. (2002). The neural basis of human error processing: Reinforcement learning, dopamine, and the error-related negativity. Psychological Review, 109, 679-709. doi:10.1037/0033-295X.109.4.679

Isella, V., Mapelli, C., Morielli, N., Pelati, O., Franceschi, M., \& APPOLlONIO, I. M. (2008). Age-related quantitative and qualitative changes in decision making ability. Behavioral Neurology, 19, 59-63. 
Juncos-Rabadán, O., Pereiro, A. X., \& Facal, D. (2008). Cognitive interference and aging: Insights from a spatial stimulus-response consistency task. Acta Psychologica, 127, 237-246. doi:10.1016/j .actpsy.2007.05.003

KaAsinen, V., \& Rinne, J. O. (2002). Functional imaging studies of dopamine system and cognition in normal aging and Parkinson's disease. Neuroscience \& Biobehavioral Reviews, 26, 785-793.

Kaasinen, V., Vilkman, H., Hietala, J., Någnen, K., Helenius, H., Olsson, H., ET AL. (2000). Age-related dopamine D2/D3 receptor loss in extrastriatal regions of the human brain. Neurobiology of Aging, 21, 683-688.

King-Casas, B., Tomlin, D., Anen, C., Camerer, C. F., Quartz, S. R., \& Montague, P. R. (2005). Getting to know you: Reputation and trust in a two-person economic exchange. Science, 308, 78-83. doi:10.1126/science. 1108062

Knight, M., Seymour, T. L., Gaunt, J. T., Baker, C., Nesmith, K., \& Mather, M. (2007). Aging and goal-directed emotional attention: Distraction reverses emotional biases. Emotion, 7, 705-714. doi:10.1037/1528-3542.7.4.705

Knutson, B., \& CoOper, J. C. (2005). Functional magnetic resonance imaging of reward prediction. Current Opinion in Neurology, 18, 411417.

Knutson, B., Taylor, J., Kaufman, M., Peterson, R., \& Glover, G. (2005). Distributed neural representation of expected value. Journal of Neuroscience, 25, 4806-4812. doi:10.1523/ JNEUROSCI.0642-05.2005

Knutson, B., Westdorp, A., Kaiser, E., \& Hommer, D. (2000). fMRI visualization of brain activity during a monetary incentive delay task. NeuroImage, 12, 20-27. doi:10.1006/nimg.2000.0593

Kovalchik, S., Camerer, C. F., Grether, D. M., Plott, C. R., \& Allman, J. M. (2005). Aging and decision making: A comparison between neurologically healthy elderly and young individuals. Journal of Economic Behavior \& Organization, 58, 79-94. doi:10.1016/j .jebo.2003.12.001

Krueger, F., McCabe, K., Moll, J., Kriegeskorte, N., Zahn, R., STRENZIOK, M., ET AL. (2007). Neural correlates of trust. Proceedings of the National Academy of Sciences, 104, 20084-20089. doi:10.1073/ pnas.0710103104

LAMAR, M., \& Resnick, S. M. (2004). Aging and prefrontal functions: Dissociating orbitofrontal and dorsolateral abilities. Neurobiology of Aging, 25, 553-558. doi:10.1016/j.neurobiolaging.2003.06.005

LECLERC, C. M., \& Kensinger, E. A. (2008). Age-related differences in medial prefrontal activation in response to emotional images. Cognitive, Affective, \& Behavioral Neuroscience, 8, 153-164. doi:10.3758/ CABN.8.2.153

Lee, T. M. C., Leung, A. W. S., Fox, P. T., GaO, J.-H., \& Chan, C. C. H. (2008). Age-related differences in neural activities during risk taking as revealed by functional MRI. Social Cognitive \& Affective Neuroscience, 3, 7-15. doi:10.1093/scan/nsm033

Li, S.-C., Biele, G., Mohr, P. N. C., \& Heekeren, H. R. (2007). Aging and neuroeconomics: Insights from research on neuromodulation of reward-based decision making. Analyse \& Kritik, 29, 97-111.

Li, S.-C., Lindenberger, U., \& SiKström, S. (2001). Aging cognition: From neuromodulation to representation. Trends in Cognitive Sciences, 5, 479-486.

MacPherson, S. E., Philips, L. H., \& Della Sala, S. (2002). Age, executive function, and social decision making: A dorsolateral prefrontal theory of cognitive aging. Psychology \& Aging, 17, 598-609. doi:10.1037/0882-7974.17.4.598

Marschner, A., Mell, T., Wartenburger, I., Villringer, A., Reischies, F. M., \& Heekeren, H. R. (2005). Reward-based decision-making and aging. Brain Research Bulletin, 67, 382-390. doi:10.1016/j.brainresbull.2005.06.010

Mata, R., Schooler, L. J., \& Rieskamp, J. (2007). The aging decision maker: Cognitive aging and the adaptive selection of decision strategies. Psychology \& Aging, 22, 796-810. doi:10.1037/0882 $-7974.22 .4 .796$

Mather, M. (2006). A review of decision making processes: Weighing the risks and benefits of aging. In L. L. Carstensen \& C. R. Hartel (Eds.), When I'm 64: Committee on aging frontiers in social psychology, personality, and adult developmental psychology (pp. 145-173). Washington, DC: National Academies Press.

Mather, M., \& KNight, M. (2005). Goal-directed memory: The role of cognitive control in older adults' emotional memory. Psychology \& Aging, 20, 554-570. doi:10.1037/0882-7974.20.4.554

Matochik, J. A., Chefer, S. I., Lane, M. A., Woolf, R. I., Morris, E. D., IngRAM, D. K., ET AL. (2000). Age-related decline in striatal volume in monkeys as measured by magnetic resonance imaging. Neurobiology of Aging, 21, 591-598. doi:10.1016/S0197-4580(00)00134-2

Matthews, S. C., Simmons, A. N., Lane, S. D., \& Paulus, M. P. (2004). Selective activation of the nucleus accumbens during risktaking decision making. Brain Imaging, 15, 2123-2127.

McCabe, K., Houser, D., Ryan, L., Smith, V., \& Trouard, T. (2001). A functional imaging study of cooperation in two-person reciprocal exchange. Proceedings of the National Academy of Sciences, 98, 11832-11835. doi:10.1073/pnas.211415698

Mell, T., Heekeren, H. R., Marschner, A., Wartenburger, I., Villringer, A., \& Reischies, F. M. (2005). Effect of aging on stimulus-reward association learning. Neuropsychologica, 43, 554563. doi:10.1016/j.neuropsychologia.2004.07.010

Montague, P. R., \& Berns, G. S. (2002). Neural economics and the biological substrates of valuation. Neuron, 36, 265-284.

Montague, P. R., \& Lohrenz, T. (2007). To detect and correct: Norm violations and their enforcement. Neuron, 56, 14-18. doi:10.1016/j .neuron.2007.09.020

Nieuwenhuis, S., Ridderinkhof, K. R., Talsma, D., Coles, M. G. H., Holroyd, C. B., KoK, A., \& van der Molen, M. W. (2002). A computational account of altered error processing in older age: Dopamine and the error-related negativity. Cognitive, Affective, \& Behavioral Neuroscience, 2, 19-36.

Pan, W.-X., Schmidt, R., Wickens, J. R., \& Hyland, B. I. (2005). Dopamine cells respond to predicted events during classical conditioning: Evidence for eligibility traces in the reward-learning network. Journal of Neuroscience, 25, 6235-6242. doi:10.1523/ JNEUROSCI.1478-05.2005

Rangel, A., Camerer, C., \& Montague, P. R. (2008). A framework for studying the neurobiology of value-based decision making. Nature Reviews Neuroscience, 9, 545-556. doi:10.1038/nrn2357

Raz, N., Lindenberger, U., Rodrigue, K. M., Kennedy, K. M., Head, D., Williamson, A., ET AL. (2005). Regional brain changes in aging healthy adults: General trends, individual differences and modifiers. Cerebral Cortex, 15, 1676-1689. doi:10.1093/cercor/bh1044

Raz, N., Rodrigue, K. M., Kennedy, K. M., Head, D., GunningDixon, F., \& Acker, J. D. (2003). Differential aging of the human striatum: Longitudinal evidence. American Journal of Neuroradiology, 24, 1849-1856.

Raz, N., Williamson, A., Gunning-Dixon, F., Head, D., \& Acker, J. D. (2000). Neuroanatomical and cognitive correlates of adult age differences in acquisition of a perceptual-motor skill. Neuroimaging \& Memory, 51, 85-93.

Resnick, S. M., LAMAR, M., \& Driscoll, I. (2007). Vulnerability of the orbitofrontal cortex to age-associated structural and functional brain changes. Annals of the New York Academy of Sciences, 1121, 562-575. doi:10.1196/annals.1401.027

Reuter-Lorenz, P. A. (2002). New visions of the aging mind and brain. Trends in Cognitive Sciences, 6, 394-400. doi:10.1016/s1364 $-6613(02) 01957-5$

Reuter-Lorenz, P. A., \& Lustig, C. (2005). Brain aging: Reorganizing discoveries about the aging mind. Current Opinion in Neurobiology, 15, 245-251. doi:10.1016/j.conb.2005.03.016

Rilling, J. K., Sanfey, A. G., Aronson, J. A., Nystrom, L. E., \& Cohen, J. D. (2004). The neural correlates of theory of mind within interpersonal reactions. NeuroImage, 22, 1694-1703. doi:10.1016/j .neuroimage.2004.04.015

Rogers, R. D., Tunbridge, E. M., Bhagwagar, Z., Drevets, W. C., Sahakian, B. J., \& CARTer, C. S. (2003). Tryptophan depletion alters the decision-making of healthy volunteers through altered processing of reward cues. Neuropsychopharmacology, 28, 153-162. doi:10.1038/sj.npp.1300001

Rolls, E. T. (2004). The functions of the orbitofrontal cortex. Brain \& Cognition, 55, 11-29. doi:10.1016/S0278-2626(03)00277-X

Ruffman, T., Henry, J. D., Livingstone, V., \& Philips, L. H. (2008). A meta-analytic review of emotion recognition and aging: Implications for neuropsychological models of aging. Neuroscience \& Biobehavioral Reviews, 32, 863-881. doi:10.1016/j.neubiorev.2008.01.001 Samanez-Larkin, G. R., Gibbs, S. E. B., Khanna, K., Nielsen, L., 
Carstensen, L. L., \& Knutson, B. (2007). Anticipation of monetary gain but not loss in healthy older adults. Nature Neuroscience, 10, 787-791. doi: $10.1038 / \mathrm{nn} 1894$

SAnfey, A. G. (2007a). Decision neuroscience: New directions in studies of judgement and decision making. Current Directions in Psychological Science, 16, 151-155. doi:10.1111/j.1467.8721.2007.00494.x

SANFEY, A. G. (2007b). Social decision-making: Insights from game theory and neuroscience. Science, 318, 598-602. doi:10.1126/ science. 1142996

Sanfey, A. G., Loewenstein, G., McClure, S. M., \& Cohen, J. D. (2006). Neuroeconomics: Cross-currents in research on decisionmaking. Trends in Cognitive Sciences, 10, 108-116. doi:10.1016/j tics.2006.01.009

Sanfey, A. G., Rilling, J. K., Aronson, J. A., Nystrom, L. E., \& Cohen, J. D. (2003). The neural basis of economic decision-making in the Ultimatum Game. Science, 300, 1755-1758. doi:10.1126/ science. 1082976

SAXE, R. (2006). Uniquely human social cognition. Current Opinion in Neurobiology, 16, 235-239. doi:10.1016/j.conb.2006.03.001

Schmitt-Eliassen, J., Ferstl, R., Wiesner, C., Deuschl, G., \& WITT, K. (2007). Feedback-based versus observational classification learning in healthy aging and Parkinson's disease. Brain Research, 1142, 178-188. doi:10.1016/j.brainres.2007.01.042

Schott, B. H., Niehaus, L., Wittmann, B. C., Schütze, H., Seidenbecher, C. I., Heinze, H.-J., \& Düzel, E. (2007). Ageing and early-stage Parkinson's disease affect separable neural mechanisms of mesolimbic reward processing. Brain, 130, 2412-2424. doi:10.1093/ brain/awm 147

Schultz, W. (2000). Multiple reward signals in the brain. Nature Reviews Neuroscience, 1, 199-209.

Schultz, W. (2002). Getting formal with dopamine and reward. Neuron, 36, 241-263.

Schultz, W., Dayan, P., \& Montague, P. R. (1997). A neural substrate of prediction and reward. Science, 275, 1593-1599. doi:10.1126/ science. 275.5306 .1593

Schweighofer, N., Tanaka, S. C., \& Doya, K. (2007). Serotonin and the evaluation of future rewards: Theory, experiments, and possible neural mechanisms. Annals of the New York Academy of Sciences, 1104, 289-300. doi:10.1196/annals.1390.011

Shohamy, D., Myers, C. E., Grossman, S., Sage, J., Gluck, M. A., \& POLDRACK, R. A. (2004). Cortico-striatal contributions to feedbackbased learning: Converging data from neuroimaging and neuropsychology. Brain, 127, 851-859. doi:10.1093/brain/ahw100

Slessor, G., Phillips, L. H., \& Bull, R. (2007). Exploring the specificity of age-related differences in theory of mind tasks. Psychology \& Aging, 22, 639-643. doi:10.1037/0882-7974.22.3.639

Sowell, E. R., Peterson, B. S., Thompson, P. M., Welcome, S. E., Henkenius, A. L., \& Toga, A. W. (2003). Mapping cortical change across the human life span. Nature Neuroscience, 6, 309-315. doi: $10.1038 / \mathrm{nn} 1008$

Stout, J. C., Rodawalt, W. C., \& Siemers, E. R. (2001). Risky decision making in Huntington's disease. Journal of the International Neuropsychological Society, 7, 92-101. doi:10.1017/s1355617701711095

Suri, R. E., BARgas, J., \& ARBIB, M. A. (2001). Modeling functions of striatal dopamine modulation in learning and planning. Neuroscience, 103, 65-85.

Sutter, M., \& Kocher, M. G. (2007). Trust and trustworthiness across different age groups. Games \& Economic Behavior, 59, 364-382. doi:10.1016/j.geb.2006.07.006

TanaKa, S. C., Doya, K., OKada, G., Ueda, K., OKamoto, Y., \& YaMAWAKI, S. (2004). Prediction of immediate and future rewards differentially recruits cortico-basal ganglia loops. Nature Neuroscience, 7, 887-893. doi:10.1038/nn1279

Tobler, P. N., Fiorillo, C. D., \& Schultz, W. (2005). Adaptive coding of reward value by dopamine neurons. Science, 307, 1642-1645. doi: $10.1126 /$ science. 1105370

Tsuchida, J., Kubo, N., \& KoJIma, S. (2002). Position reversal learning in aged Japanese macaques. Behavioural Brain Research, 129, $107-$ 112. doi:10.1016/so166-4328(01)00336-9

van Winden, F., Stallen, M., \& Ridderinkhof, K. R. (2008). On the nature, modeling, and neural bases of social ties. In D. Houser \& K. McCabe (Eds.), Neuroeconomics (pp. 125-159). Bingley, U.K.: Emerald.

Walhovd, K. B., Fuell, A. M., Reinvang, I., Lundervold, A., Dale, A. M., Eilertsen, D. E., ET AL. (2005). Effects of age on volumes of cortex, white matter and subcortical structures. Neurobiology of Aging, 26, 1261-1270. doi:10.1016/j.neurobiolaging.2005.05.020

Wang, G. J., Volkow, N. D., Logan, J., Fowler, J. S., Schlyer, D., MACGREGOR, R. R., ET AL. (1995). Evaluation of age-related changes in serotonin 5-HT2 and dopamine D2 receptor availability in healthy human subjects. Life Sciences, 56, L249-L253.

Weiler, J. A., Bellebaum, C., \& Daum, I. (2008). Aging affects acquisition and reversal of reward-based associative learning. Learning \& Memory, 15, 190-197. doi:10.1101/1m890408

Wood, S., Busemeyer, J., Koling, A., Davis, H., \& Cox, C. R. (2005). Older adults as adaptive decision-makers: Evidence from the Iowa Gambling Task. Psychology \& Aging, 20, 220-225. doi:10.1037/0882 $-7974.20 .2 .220$

Woodruff-PaK, D. S. (1997). The neuropsychology of aging. Cambridge, MA: Blackwell.

Zacks, R. T., RadVAnSKy, G., \& Hasher, L. (1996). Studies of directed forgetting in older adults. Journal of Experimental Psychology: Learning, Memory, \& Cognition, 22, 143-156.

(Manuscript received October 29, 2008; revision accepted for publication July 31, 2009.) 